I have the permission of a colleague to quote the following case, which I saw while it was under his care at another hospital in 1906 .

July 12th. A. E. S., aged 21 months, inhaled a pea into the left bronchus; had a very violent bout of coughing, turned black in the face.

July 19th. Admitted to dispensary; diagnosis of pneumonia made ; Jater, dry paracentesis.

July 28th. Sent on to hospital ; diagnosis, (?) empyema.

August 5 th. History of inhalation of pea picked up from the floor obtained for the first time from the parents. Skiagram shows opacity of left lung, displacement of the heart to the left.

August 6th. Low tracheotomy, exploration of left bronchus, no obstruction or foreign body found.

August 28th. Paracentesis of left chest, half a drachm of blood-stained serum removed. Impaired note, weak breath sounds, occasional râle over the whole of the left lung ; (?) pulmonary tuberculosis.

September 19th. Paracentesis, a little pus withdrawn.

September 20th. Operation, piece of sixth left rib. removed half an ounce of pus drained from a ragged cavity, no empyema found. Tube.

October 2nd. Death from wasting and exhaustion; irregular hectic fever since Juiy 19th, occasional bouts of cough ending in vomiting. The left lung was found to be densely adherent, enlarged, airless, and on section consposed of a honeycombed series of small bronchiectatic cavities filled with thick in offensive green pus, with collapsed lung tissue in between. No bronchial obstruction or ulceration found. Corresponding to empyema operation, a small raggel cavity, into which pus could be squeezed from the adjoining lung.

I imagino that the interpretation of this case would be that the child inhaled a dirty and insalivated pea into its left bronchus on July 12th and developed an acute septic bronchitis on the left side, passing rapidly on to bronchiectasis. The pea must have been got rid of before August 6th.

Treatment.

In all cases inversion of the patient, or letting him cougl with his head and chest hanging downwards so as to facilitate the emptying of his bronchiectatic cavities, is a serviceable practice, best carried out on waling. For the rest the treatment of bronchiectasis may be either medical or surgical. The medical treatment aims at combating the infection in the bronchial tubes by antiseptics, the most widely used of wbich is creosote. The creosote may be administered in three ways: (1) By the mouth in capsule form; absorbed from the alimentary tract, some of the creosote is excreted into the lungs, and may there act as an antiseptic. I have never seen much good result from this mode of treatment, and it has the disadvantage of tending to upset the stomach. (2) By intratracheal injection; creosote, thymol, menthol, or some other organic antiseptic, dissolved in five or ten parts of olive oil, is injected into the trachea through the curred nozzle of a syringe, below the vocal cords, after cocainization of the pharynx and larynx. A few drachms of the oily antiseptic can be introduced thus daily, in the hope that some of it will gravitate into the dilated tubes and help to sterilize them and their contents. In the few cases in which I have seen it tried this treatment has not proved strikingly successful. (3) By inlualation; up to a point this method gives admirable results, of a palliative order. The creosote, mixed perhaps in equal parts with eucalyptus oil and oleum pini silvestris, may be given on a Burney Yeo inhaler, worn for many hours a day. A more effective method of administratiou is to have a small closed chamber in which creosote can be volatilized by heat; the patient, his eyes protected from the pungent vapour by goggles, inhales the white clouds of creosote fumes deep into his lungs. The fumes bring on violent coughing which enupties the dilated tubes, and no doubt also exert a beneficial antiseptic action on their infected and inflamed walls. A creosote vapour bath can be given daily, at first for five minutes only, but after practice for fifteen or twenty minutes; care should be taken to see that the fumes are not too strong, and that the creosote is not carbonized by overheating the dish from which it is evaporated in the creosote chamber. The benefits to be expected from this treatment are a great reduction in the quantity of the sputum, which often falls from 20 to 30 ounces a day to 2 or 3 ; loss of its offensive odour; diminution in the patient's fever; and much improvement in his appetite and general condition. But in the great majority of cases it is palliative only, and relapse is likely to follow its dis. continuance. It would be interesting to know the result of the treatment of bronchiectasis by the inhalation of a 2 per cent. solution of, say, Dakin's chloramine-'T sprayed into the air by a steam atomizer-a treatment that proved successful a few years ago in the steri'ization of the nasopharynx of carriers of the meningococcus.

The surgical treatment of bronchiectasis consists in the operative removal of many inches each from a large number of ribs over the brouchiectatic lung, in order that it may be made to fall in completely and obliterate the bronchiectatic cavities by fibrosis and collapse. Tho operation is obviously very severe, and it has been prac tised on the Continent, and particulatly in Scandinavia, much more frequently than in this country, and usually under local-not general-anaesthesia. It is applicablo only to unilateral cases of bronchiectasis, preferably thos in which the lower lobe of the lung is involved, and $t_{1}$ those not due to bronchial obstruction by new growth o aneurysm. I have hitherto had occasion to recommen it in two cases only, in 1917; in one the result was un fortunate, in the other excellent; the patient has beer able to return to work for the last six months, and the sputum has been reduccd to half an ounce of inoffensivo muco-pus brought up on rising. Three successive partial removals of ribs were performed in this instance, and extensive collapse of the affected lung has been. effected.

\section{THE EPIDEMIOLOGY OF PHTHISIS.}

WILLIAM GORDON, M.D., F.R.C.P., PHYSICIAN TO THE DEVON AND EXETER HOSPITAL.

I HAVE read with great interest Dr. Brownlce's recent papers on "The epidemiology of phthisis in Great Britain and Ireland," 1 and, as they bear" upcn some of my own work on the climatology of phthisis, I should like to say something about them.

Part I.-Phthisis Death Rates at Different Ages.

First of all I would congratulate Dr. Brownlee on havins introduced into the investigation of phthisis-prevalence a new method of comparing death rates at successive ago periods-a method likely to yield very interesting and valuable information.

\section{Phthisis not a Single Disease.}

Dr. Brownlee concludes, from a study of the age curves of male mortalities, that phthisis can no longer be regarded as a single disease, but that two or perhaps three types are to be recognized, "distinguished by the characters of their incidence at different ages" ; death most commonly occurring in one type between 20 and 25 , in another type between 45 and 50 , and perhaps in a third type between 55 and 65.

Obviously this is a proposition which can only be accepted on the most convincing evidence, for the conception of age selective types is quite a different thing from the conception of such types as are met with in the diseases to which reference is made in his paper-namely, enteric, bacillary dysentery, tetanus, pneumonia, and cerebro-spinal fever-types which do not select different ages for their attack. Moreover, since we shall find that the male curves differ from the female curves for the same districts, in such a way that the further assumption is needed that his types of phthisis are not merely age selective, but to some extent sex selective as well, the difference between them and the types of those other diseases becomes still more pronounced.

Also it must be romembered that neither clinicians nor bacteriologists have any lknowledge of the existence of separate types of "human" tubercle bacilli.

Now nothing has impressed itself so strongly on my mind, in the course of my work on phthisis environment, as the conviction that, if the subject is to be raised out of the chaos of mere surmise in which it has always been in volved, and if it is to be placed on a solid scientific basis, a principle, which I have called "the principle of the approxi. mate isolation of influences," wust be recognized thind applied. ${ }^{2}$ By such "approximate isolation" I mean the enumeration of all possible appreciable conflicting influesces and their successive elimination from the problem so far as that is possible. I need not illustrate the various ways 
in which such eliminations can be carried out, as abundant illustrations exist in my publications. That the idea is feasible and effective has been amply demonstrated.

Of the many influences known to affect the prevalence of phthisis, one of the most powerful is the influence of occupation; and occupation is generally far more diverse, and therefore far more disturbing, among males than among females. To eliminate it as far as possible, only female death-rates should be primarily considered. In my work I have been most careful, wherever possible, to deal with female death - rates only, and I have no sort of doubt of the advantage of so doing.

I would suggest therefore considering the corresponding age curves for female phthisis death-rates in the areas which Dr. Brownlee has chosen for lis dia. grams.

Fig. 1 shows the result of comparing the female age curves of all the English areas for the decade 1881-90, and Fig. 2 shows the same for the Scottish areas and Ireland for 1881 to 1900 ; the latter

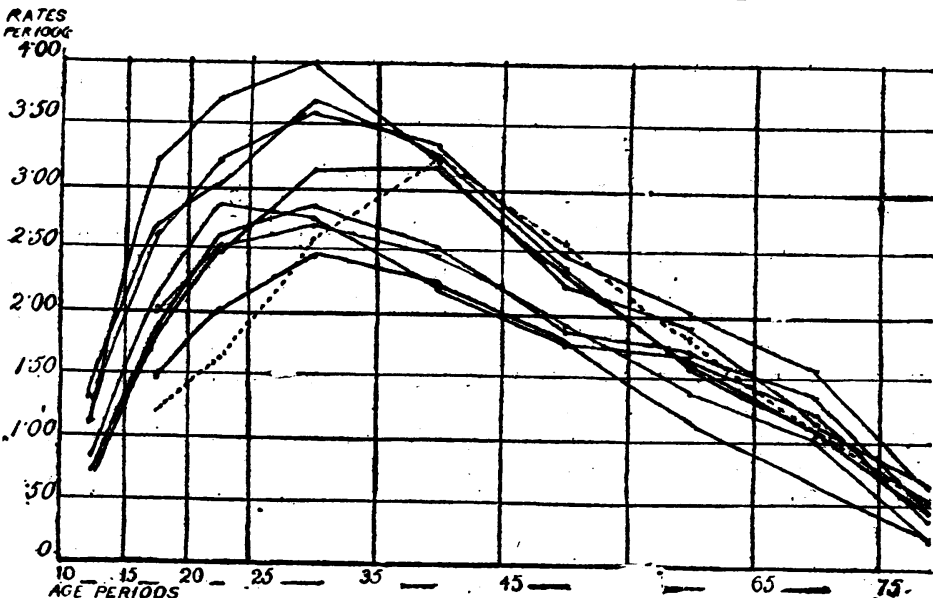

Frg. 1.-Female phthisis death-rates, 1881-90. The curves, in order from above downwards, as they cut the 25 to 35 eo-ordinate line, are those of North Wales, Northumberland, Bouth Wales, Lancashire, Devon, Cornwall.

Therefore I strongly incline to the view that the differences in the male curves are due, not to differences in the organism of phthisis but to differences of occupation and of density of population affecting the predisposition of the male inhabitants to invasion by the disease.

Part II.-Decline in Phthisis Mortality dof to the Inherent Biological Properties of the Disease.

In the second part of his investigation Dr. Brownlee attributes the un. doubted decline in phthisis prevalence in England during the last seventy years (and perhaps before that) not to any change, sanitary or other, in its environment, but to "the ebb of a long epidemic wave" due to "the inherent biological properties of the disease.'

I am afraid, on the evidence, which he sub. mits to us with ad. mirable candour, we cannot accept so sweeping a conclusion. It might be as he says, but such figures cannot prove it. He has, however, in Part III, himself de gives the curves supplied by Dr. Brownlee himself in his Diagrams 14 to 17 and 19, curves in the former have been calculated for the first decade of the same period.

From a study of these curves I do not think one would be justified in deducing the existence of two or three types of "human" tuberculosis. The top of the curve, in nearly every area, lies between the ages of 25 and 35 . Only Ireland and Cornwall have carves culminating five years earlier; only London lias ove culminating between 35 and 45; Lancashire and Midlothian show a level summit from 25 to 45 . Surely, if two or three types of phthisis existed, they would manifest themselves in the female curves more plainly than thiss.

From all the fore going considerations I cannot but conclude that some conflicting influence or influences have modified the male curves and given rise to mistake. I believe that this is the case, and, from f o r m er experience suspect that the in fluences of occupation and density of popula. tion are the delin quents.

For if we re. examine the..male curves given by Dr. Brownlee we find that those which culminate

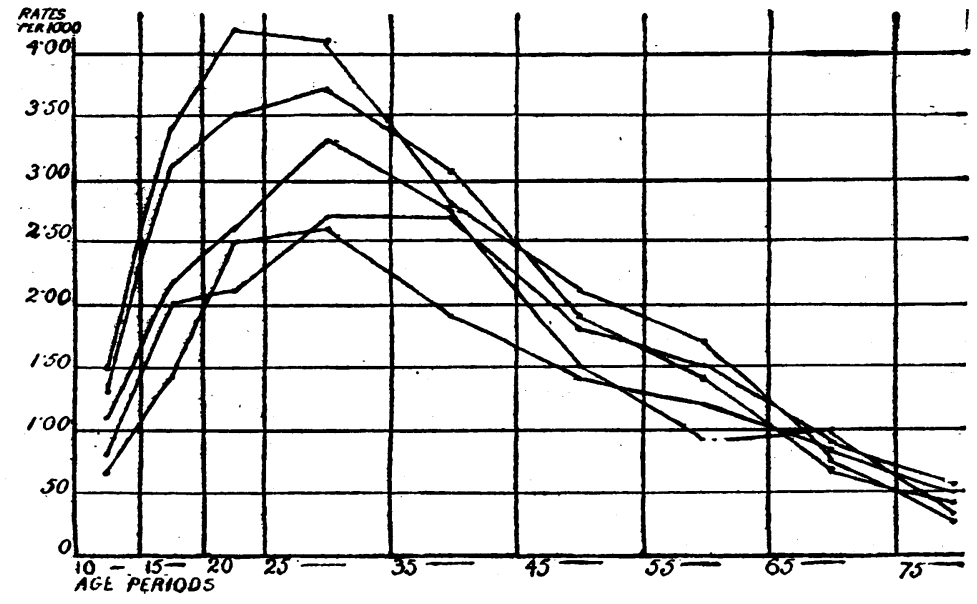

Fig. 2.-Fomale phthisis death-rates, 1831-1900. (From Dr. Buchanan's Diagrams 14-17 and 19.) The curves, in order from above downwards, as they cut the 25 tr 35 co-ordinate line, are those of Ireland, Lanark, etc., Shetland. Midlotbian, etc., Caithness, etc. in early adult life-Shetland, Caithness to Argyll, Norfolk, Devon, North Wales, South Wales-belong to arcas to which outdoor occupations in open country are predominant, wheress the curves which culminate at middle life-Stafford, Lancashire, London, Midlothian including Edinburgh-belong to areas in which indoor occupations in towns are predominant; also it will be observed in the diagrams of the male curves, in areas where, as time has gone on, industrial life in towns has grown at the expense of outdoor life in the country - Staffordshire, Lancashire, England and Wales generally-the summits of the curves have tended to $s$ weep in successive decades towards higher ages. molished the idea. For his evidence was obtained from the Mortality Bills of London, and yet here he has supplied us with a very valuable proof that the decline of phthisis death-rate in London is due chiefly, if not solely, to improved hygiene. "Phthisis," he writes, "has not decreased in London during the epoch for which accurate knowledge is available, except so far as the general improvement in lygiene would explain." 3

\section{Part III.-Strone Prevalent Rainy Winds and} Phthisis.

In one section of Part III Dr. Brownlee has ably re. investigated my work in Deronshire on rain bearing winds and phthisis, using dif. ferent periods to mine, and has added to the value of my proof by the manner of his confirmation. I am very grateful to him for doing what for many a day I vainly hoped someone would do-fairly take in hand the proof or disproof of my conten. tion. His courteous reference to my work I cordially appreciate.

His confirmation of this work is clearly of very far-reaching importance; for the influence on plitlisis of strong prevalent rain-bearing winds is a very powerful influence and needless to say, if it is admitted to bo exercised in Deronshire, it must be also admitted to be exercised elsewhere, wherever those winds are met with. So important do $I$ consider this influence, and so lamentable the results, scientific and practical, which have flowed from ignorance of it, that I make no apology for very brietly summarizing here the mass of evidence now accumulated on the matter.

1. Evidence from Many Parts of the World.'All over the world, wherever sufficiently reliable information was available, I collected lata for examining into the relations of wind and phthisis. This work was done less in search 
of confirmation than in seeking for exceptions whose existence would point to some fallacy in my proof. No such exceptions were found, but much valuable and interesting confirmation was forthcoming.

2. Effect of these Winds on Phthisis Patients. ${ }^{5}$ Cases of phthisis in Devonshire exposed to these winds have been shown to run a shorter course than cases sheltered from them. Unpublished clinical evidence also has accumulated pointing strongly in the same direction. I have also tried to compare the statistics from variously placed sanatoriums; this proved impossible, but it was significant that some exceptionally exposed sanatoriums kept no records of results! There seems to me no doubt that some at least of the disappointment generally expressed with the results of sanatorium treatment in this country is due to the ill-chosen sites of some of our sanatoriums.

Perhaps now that an able independent investigator has confirmed my conclusions, a little pains may be taken to place the new sanatoriums for our phthisical sailors and soldiers in situations where failure shall be less of a foregone conclusion!

3. Effect of these Winds on Bovine Tuberculosis.Bovine tuberculosis is much commoner in areas exposed to strong rain-bearing winds than in areas sheltered from them. ${ }^{6}$ Professor 'Delépine's valuable paper ${ }^{7}$ on tuberculosis in the farms supplying Manchester with milk gave me a unique epportunity of investigating this im. portant point. This fact surely calls for some attention.

4. Altitude and Phthisis. - When the influence of rain bearing winds had been taken into account and, as far as possible, eliminated by considering only localities sheltered from them, the contradictions, which had rendered a satis factory conclusion on the relations of altitude and phthisis prevalence impossible, disappeared, and the important generalization was reached that altitide, per se, has no influence on phthisis prevalence. 'The fact is that, as altitude increases, exposed situations increase so much in bleakness that the population is more and more forced into shelter; consequently, as altitude increases the proportion of the population living in shelter increases and the pre valence of phthisis falls. This conclusion does not affect my belief in the beneficial effect of high altitudes in shelter on phthisis patients.

5. Subsoil and Phthisis.-Dr. Brownlee must hava given my papers on this subject a very hasty glance, or he would have recognized that not only did it deal with a much more extensive field than Buclianan's-all England as against three counties-but that it was much more elaborate and safeguarded from error; also (most important of all) that instead of leaving the question one of mere surmise, mine left it practically proved that certain geological formations are definitely associated with higher phthisis death rates than others. I say "practically" proved because, until larger populations in pronounced shelter from rain-hearing winds have been dealt with, I shall not consider the investigation complete. Dr. Brown lee's results in Norfolls, Suffollk, and Essex are very suggestive, but, in view of the varying exposures of his districts, must bə regarded as incouclusive.

6. Occupation and Phthisis.-I wrote in $1913^{10}$ : "The evil eminence of the tin-miner may not be entirely occupational; he lives for the most part in a district swept by strong rainy winds. Also the Midland coal-miner, who suffer's less from phthisis than coal-miners in other parts of England, may not orve his good fortune altogether to the conditions of his work, but partly also to the slighter exposure of his district to rain-bearing winds."

7. Density of Population and Plthisis. "I have shown that in certain rainy wind-swept regions the self-protection of a town from wiuds may more than compensate for its comparative crowding.

\section{Phthisis in Wales.}

Dr. Brownlee's section on this subject is instructive and interesting. But I fear he will find the problem of subsoil in Wales as disappointing as he found his Welsh study of rainy winds. I have tried it myself, for I observed how heavy. were the death rates on some of the Welsh forma. tions. Rainy winds, race, modes of life and occupation, seem perversely arranged so as to confuse the problem and almost to defy elimination. It will bo observed that Dr. Brownlee's map of the districts is almost as suggestive of the effect of rain-bearing wind as of subsoil, when it is remembered that in the east and south-east of Wales the mountains afford much slselter, and that, in the south-east, occupation must modify the figures, the phthisis death rate of coal-miners generally tending to be low. Ny table of the phthisis death rates in the Welsh registration districts, 1881-90,11 indicates at least some effect produced by rainbearing winds.

\section{A Misapprehension.}

Before concluding, I should like to clear up a mis. apprehension. Dr. Brownlee has referted to me as a "follower in Haviland's footsteps." So far from being a follower of Haviland, I was fortunately quite unaware of his work until I had found the fact on which I lay such stress. Haviland's statements were quite different from mine, and, had I been familiar with them, it is not unlikely that I should have missed my point, as he did.

Summary.

1. Dr. Brownlee has introduced a new method of inresti. gating phthisis death rates at successive age periods which promises to be valuable.

2. He has not proved his first proposition regarding the existence of two or three types of human tubercle.

3. He has himself disproved his second proposition, dealing with the cause of the decline of phthisis.

4. His confirmation of my conclusions in Devoushire in respect of the influence of strong prevalent rain-bearing winds on the prevalence of phthisis, once more emphasizes the necessity for recognizing this influence.

5. Incidentally his papers illustrate the need for applying, in climatological research, what I have called "the principle of approximate isolation of influences."

1 An Investigation into the Epidemiology of Phthisis in Great An Investigation into the Epidemiology of Phthisis in G Geat
Britain and Ireland, Parts 1 and 2, $1918 ;$ Part 3,1920, Medical Research Committee. 2 The Inftuence of Strong; Prevalent Ritin-bearing IVind on the Prevalence of Phthisis. London, Lewis, 1910 . p. 11 . M Part 3 , p. 36. 4 The Influence of Strong Prevalent Rain-beaing Winds, the Prevalence of Plhthisis, Chanter VI. 5"BRITISH MEDICAL . IocRNaL, February 10th and April 6th, 1912. 6 JRITISH MIYDICAL JOe RNAL, March 4th, 1911. 7 Proc. Roy. Soc. Meil., vol. 3, No. 7, Jay, 1910, Epidem. Sect. ${ }^{8}$ The Place of Climatology in Medicine, London, Lewis, 1913, Lecture 2. 9 Proc. Roy. Soc. Med., 1915, vol. 9, Balneolog. and Climatolog. Sect., pp. 1 to 20 . 10 Practitioner, January, 1913, p. 7. The Influence of Strong prevalent Rain-bearing Winds on the Prevalence of Phthisis, p. 81 .

\section{FURTHER WORK ON ANTIMONY INTRA- VENOUSLY IN FILARIASIS.}

Lieut.-Colonel Sir LEONARD ROGERS, Kr., C.I.E. M.D., F.R.C.P., F.R.S., I,M.S.

LAST year I published a preliminary report on short trials of sodium antimonyl tartrate solutions injected intravenously in filariasis, and showed that the drug had some action in reducing the number of embryo filaria in the evening peripheral blood and in lessening their motility, but I had not been able to follow up the cases long enough to ascertain if the effect was permanent or not, although I had arranged to do so. Thanks to the lindness of Lieut.-Colonel Thornley, I.M.S., Civil Surgeon of Cuttack, I have now been able to follow up a series of eight cases in the central jail of that filarial infected station, with the results recorded in this communication.

Method of Investigation.

Thick blood films of 100 prisoners under sentences of three months and over were sent to me for examination, while 50 more were taken during a visit to Cuttack; all were taken at 9 p.m., which is quite late enough for Indian patients. In 18 per cent. of these healthy men filaria embryos were found, and eight, who showed from 17 to 126 embryo filaria in 20 cubic millimetres of blood and a total of 732 in the eight slides, were selected for treatment. Five controls were also taken with from 22 to 117 filaria in a slide and a total of 168 . The blood slides were taken every evening at 9 p.m. at first and later adit longer intervals, but always at the same hour, and the injections of a 2 per cent. solution of sodium antimonyl tartrate were given in the mornings. I am greatly indebted to Subassistant Surgeon Kailas Chandra Rao, demonstrator 